\title{
Driving factors of community-level plant functional traits and species distributions in the desert-wetland ecosystem of the Shule River Basin, China
}

\author{
Guanguang Chen ${ }^{1}$ | Dongxia Yue ${ }^{1}$ | | Yanyan Zhou ${ }^{1}$ | Dong Wang ${ }^{1}$ | \\ Hai Wang ${ }^{2}$ | Cang Hui ${ }^{3}$ | Jianjun Guo ${ }^{4}$
}

${ }^{1}$ College of Earth and Environmental Sciences, Lanzhou University, Lanzhou, PR China

${ }^{2}$ Dunhuang Xihu National Nature Reserve Administration, Jiuquan, PR China

${ }^{3}$ Centre for Invasion Biology, Department of Mathematical Sciences, Stellenbosch

University, African Institute for Mathematical Sciences, Matieland, South Africa

${ }^{4}$ Key Laboratory of Desert and Desertification, Northwest Institute Eco-environment and Resource, Chinese Academy of Sciences, Lanzhou, PR China

\section{Correspondence}

Dongxia Yue, College of Earth and

Environmental Sciences, Lanzhou University, Lanzhou 730000, PR China.

Email: dxyue@lzu.edu.cn

Funding information

National Key Research and Development Plan of China, Grant/Award Number:

2017YFC1501005; National Nature Science Foundation of China, Grant/Award Numbers: 41671516, 41701623; National Research Foundation, Grant/Award Number: 89967

\begin{abstract}
Groundwater, as the limiting resource in arid ecosystems, can have profound effects on the functional structure and distribution of plant communities. However, studies are too few to unveil the impacts of groundwater depth on plant functional traits in such communities. We collected data on vegetation, topography and soil properties from 180 quadrats (60 trees/shrubs and 120 herbaceous) in the desert-wetland ecosystem of Shule River Basin in Northwest China. We measured 10 key communitylevel functional traits, together with the resource topography (i.e., groundwater depth) and seven soil properties. We found that the increase of groundwater depth significantly reduced community-level specific leaf area and maximum leaf photosynthesis rate, while boosted leaf dry mass content and leaf thickness. However, the leaf phosphorus content remained relatively stable. By contrast, with the increase of groundwater depth, soil carbon, soil nitrogen, soil phosphorus and total dissolved salts first increased but then declined, while soil $\mathrm{pH}$ and soil bulk density exhibited the opposite trend. The soil moisture content decreased drastically with the decline of groundwater. The change in groundwater depth, thus, was found the main driver of species distribution in the arid zone, contributing $21.16 \%$, followed by soil $\mathrm{K}^{+}$ (9.94\%) and soil total nitrogen content (4.9\%), as well as a strong interaction of the three (41.7\%). Changes in groundwater depth can thus alter the structure and nutrient enrichment of the soil, which in turn affects the distribution of vegetation through water-soil-plant interactions.
\end{abstract}

KEYWORDS

driving factors, groundwater depth, plant functional traits, soil properties, species distribution

\section{1 | INTRODUCTION}

Plant communities in arid ecosystems are under pressure from limited water resources. Of particular interest, desert-wetland is a type of vegetation uniquely adapted to extreme arid climates. It is mainly

Guanguang Chen and Dongxia Yue contributed equally to this work. distributed in low-lying and dissolved-salt gathering areas in the tailend-lake of the inland river. Worldwide, changes in wetland function and species composition in such arid ecosystems, due to drought and water shortages, have become a serious challenge to the conservation and restoration (Charles \& Dukes, 2009; Holmstrup et al., 2012). Most arid and semiarid species depend on the capillary fringe above the groundwater for survival and growth; consequently, the decline of 
groundwater can profoundly affect the growth of individual plants and the structure of community assemblages (Chen, Chen, $\mathrm{Xu}, \&$ Li, 2016; Ma, Feng, Su, Yu, \& Deo, 2018; Smith, Devitt, Sala, Cleverly, \& Busch, 1998). Groundwater depletion due to excessive human activities (e.g., irrigation and overexploitation) and climate change has posed threats to the sustainability of vegetation in arid regions across the globe (Barbeta et al., 2015; Castle et al., 2014; Stromberg, Tiller, \& Richter, 1996). As the only water source in extremely arid regions, it is of paramount importance to understand the impacts of groundwater decline on vegetation distribution and soil properties (MunozReinoso, 2001; Zhu, Yu, Wang, Zhang, \& Yu, 2012).

Knowledge on plant functional traits provides an effective way to understand and predict changes in the distribution and composition of vegetation along environmental gradients (Castle et al., 2014; Lavorel \& Garnier, 2002; Westoby \& Wright, 2006). Past research has shown that this can be done successfully by studying species characteristics that reflect how species adapt to their environment (Douma, Bardin, Bartholomeus, \& van Bodegom, 2012). For instance, leaf trait is associated with performance and functioning of plants in terrestrial ecosystems (e.g., transpiration and carbon assimilation). The morphological traits of leaf can signal plant strategies on water use efficiency, growth pattern and nutrient use (Krober, Plath, Heklau, \& Bruelheide, 2015; Wilson, Thompson, \& Hodgson, 1999). The morphological and biochemical traits of plants can further reflect the survival and adaptive strategies for maximum carbon harvesting (Wright et al., 2004). Extending the study of leaf traits to the entire community level could help to reveal the response of regional vegetation to climate change (Wright et al., 2005). As leaf traits are relatively stable, they become a key scalar to up-scale experimental data from the leaf level to the entire community and even to the entire region (Mao et al., 2018; Reich \& Oleksyn, 2004). Previous studies have connected soil nutrients and light energy utilization with leaf traits (Migliavacca et al., 2017; Ordonez et al., 2009), with little on the effects of water stress. Nonetheless, some studies have implicitly indicated the role of water in shaping plant communities, for example, by highlighting that plants in arid environments have thicker and smaller leaves (Li et al., 2016), more leaf nitrogen content (Abrams \& Mostoller, 1995), and higher water use efficiency (Anjum et al., 2011). Although these studies have indeed provided insights on the adaptation of leaf traits to water changes, there is no clear indication on how such water-dependent leaf functional traits can also affect plant community structure, a challenge particular to the conservation in arid regions.

Ecological communities can respond to environmental disturbances and resource fluctuations by changing community structure (e.g., stratification of trees, shrubs and herbs) and species turnover (gain or loss of particular species; Carvajal, Loayza, Rios, Gianoli, \& Squeo, 2017). Such environmental stresses can further affect the performance of individual plants, modifying for instance their biomass accumulation and leaf morphology. However, in arid regions, especially those extremely arid regions, where rainfall and resources are scarce, vegetation generally only grows where nutrients are abundant. Therefore, the spatial distribution of vegetation is generally uneven and more sensitive to local soil conditions than the humidity of arid regions
(Costantini et al., 2016; Principe et al., 2014). In arid and semi-arid regions, studies have revealed that soil physical and chemical properties, for example, salinization, can affect the growth of vegetation (Kong, Sun, Chen, Yu, \& Tian, 2010; Zhang et al., 2018; Zhou, Chen, \& Li, 2010). However, different species have different demands for soil moisture and nutrients, and their roots also have different abilities to absorb water in the soil layer of different depths (Canadell et al., 1996). It is thus necessary to conduct stratification studies of soil to elucidate the relationship among vegetation, soil and groundwater depth.

The Shule River is a typical arid river basin in Northwest China. The groundwater depth in the lower reaches of the Shule River has dropped by $10.77 \mathrm{~m}$ from 1975 to 2012 . The main reason for the decline of groundwater depth is the reduction of groundwater recharge and the increasing demand from mining (Lin et al., 2018). In addition, factors such as rising temperature and climate aridization have also played a notable certain role (Yang et al., 2016). To address the challenge, an ecological water supply project, dubbed "Yin $\mathrm{Ha} \mathrm{Ji}$ Dang," is about to be officially implemented to improve the groundwater reservoir in Dunhuang. However, there is little discussion on the response of vegetation and soil properties to changes in groundwater depth in the region. Here, we explore the changes in vegetation, community-level plant traits and soil properties in response to changes in groundwater depth. We do so by conducting systematic surveys of plant communities, soils and groundwater depths in the Xihu (West Lake) National Nature Reserve on the lower reaches of the Shule River in Dunhuang. Here, we plan to, (a) document changes in plant community structures, species compositions and communitylevel weighted means (CWM) of plant functional traits along the gradient of groundwater depth; (b) explore effects of changes in groundwater depth on soil physical and chemical properties; and (c) identify environmental factors posing greater constraints on the distributions of different dominant plant species.

\section{2 | MATERIALS AND METHODS}

\section{1 | Study area}

The study area is located at the National Positioning Observation Station of wetland ecosystems in Xihu National Nature Reserve $\left(39^{\circ} 45^{\prime}\right.$ $40^{\circ} 36^{\prime} \mathrm{N} ; 92^{\circ} 45^{\prime}-93^{\circ} 50^{\prime} \mathrm{E}$, elevation $998 \mathrm{~m}$ asl., Figure 1 ), Shule River Basin, Northwest China. The mean annual precipitation (calculated using annual data from 1952 to 2005) is $39.9 \mathrm{~mm}$, while the total annual evaporation is $2,486 \mathrm{~mm}$ ( $\mathrm{Li}$ et al., 2017), defining the region an extremely arid zone of China (Figure S1). The main runoffs in the reserve are the Shule River, the Danghe River and the Nanhu Spring Water, which are basically meander cutoffs. The soil types include mainly Salic Solonetz and Gypsic Solonchaks, with some additional Yermic Arenosols and Aridic Arenosols in the Gobi Desert, as well as some meadow soils in the floodplain (Sun et al., 2016). The flora belongs to the Asian desert plant subregion in the Pan-Arctic plant area and has a distinct temperate desert climate. The major tree and shrub species include Populus euphratica, Tamarix ramosissima and 
Lycium ruthenicum. The herbaceous species are dominated by Phragmites australis, Agropyron cristatum, Apocynum venetum, Glycyrrhiza uralensis and Alhagi sparsifolia.

\section{2 | Sampling design}

Vegetation structure of the desert-wetland ecosystem is variable across the landscape, ranging from halophytic marsh grassland to typical desert woodland within groundwater gradients of approximately $50 \mathrm{~km}$ in length (note that the terrain is flat). From north to south, 15 survey belts (belongs to five different areas) were set up according to the change of vegetation types and the depth of groundwater available for vegetation (generally less than $7 \mathrm{~m}$ in depth), and groundwater monitoring wells were established, respectively (Figure 1). The dynamics of groundwater depth have been automatically monitored since 2008 at an hourly pace. The average groundwater depth was 1.07, 2.03, 2.78, 4.04 and $5.42 \mathrm{~m}$ at the five areas from April to October of 2012 to 2017 (growing season), respectively. The five areas were designated as Site1-5 (Figure S2). Within each site, $1215 \times 15 \mathrm{~m}$ quadrats were established to record the trait parameters of trees and shrubs, and $241 \times 1 \mathrm{~m}$ quadrats for herbaceous surveys. The quadrats were randomly located across the range of present communities. All edaphic and vegetation variables were obtained within these quadrats.

\section{3 | Vegetation survey}

We surveyed a total of 180 vegetation sample quadrats across all sites in July when the plant biomass has reached the maximum, including in total $6015 \times 15 \mathrm{~m}$ quadrats for trees and shrubs, and $1201 \times 1 \mathrm{~m}$ quadrats for herbaceous species. The elevation, latitude and longitude of each survey quadrat were recorded using GPS.

We measured vegetation characteristics of each $15 \times 15 \mathrm{~m}$ quadrat for trees and shrubs. For replicates of each quadrat, the height ( $>3 \mathrm{~cm}$ in height or diameter) and the number of individuals of each species was measured or counted. We also measured the diameter at breast height (measured at $1.3 \mathrm{~m}$ from the ground; TerMikaelian \& Korzukhin, 1997), basal diameter (measured at about $2 \mathrm{~cm}$ above the ground) and crown diameter of individual tree/shrub in each quadrat. For the trees, we used a laser altimeter for height measurement (LIONS W1000, accuracy $\pm 1 \mathrm{~m}$, China). The height of the remaining species was measured using a steel tape measure $( \pm 0.01 \mathrm{~m})$. For ecological protection and workload considerations, we estimated the biomass of large trees and shrubs using the species biomass models (a)

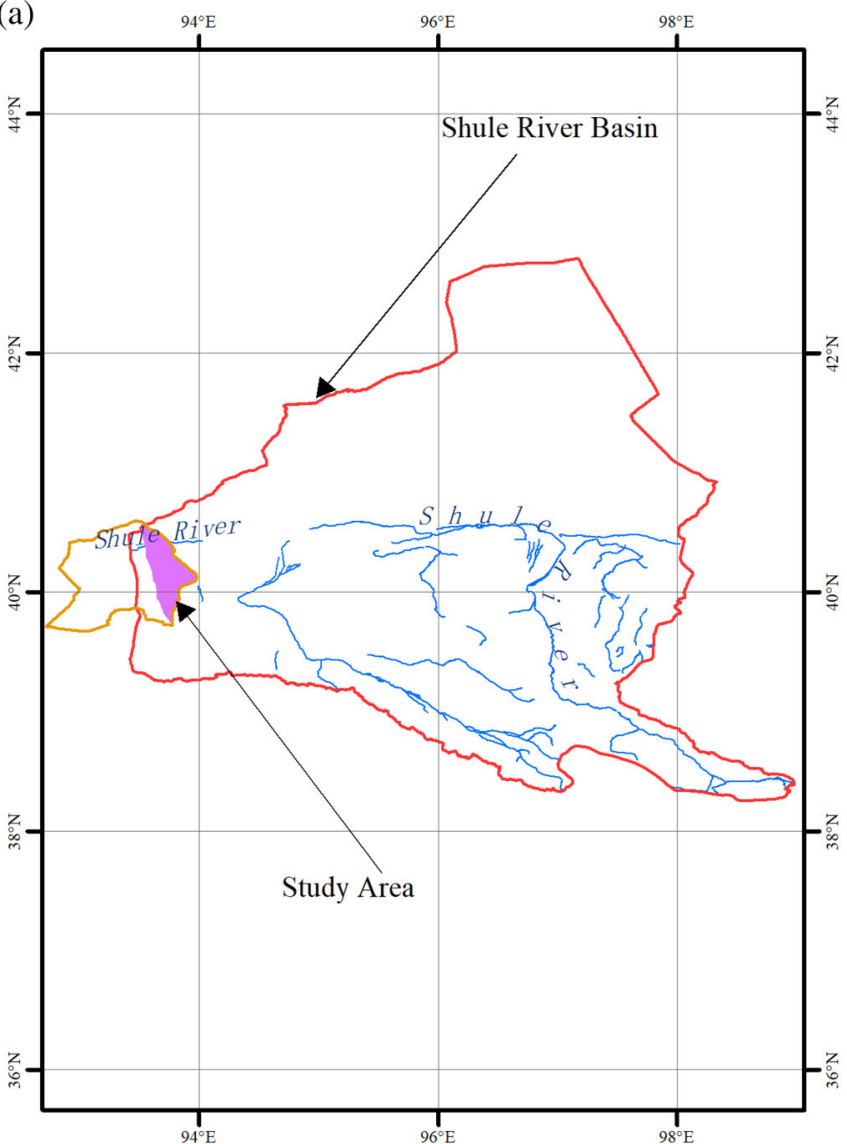

(b)

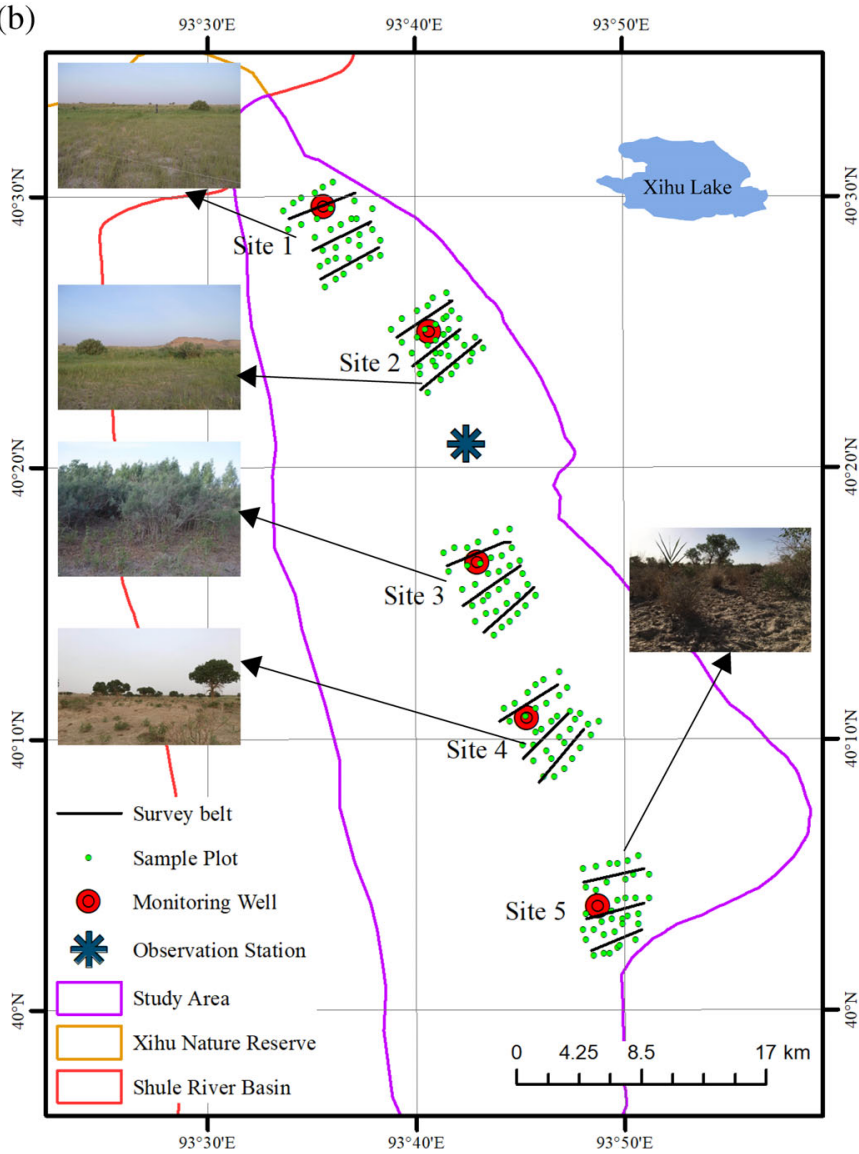

FIGURE 1 The study area (a location of the study area in Shule River Basin. b Site1-Site5 in the study area) [Colour figure can be viewed at wileyonlinelibrary.com] 


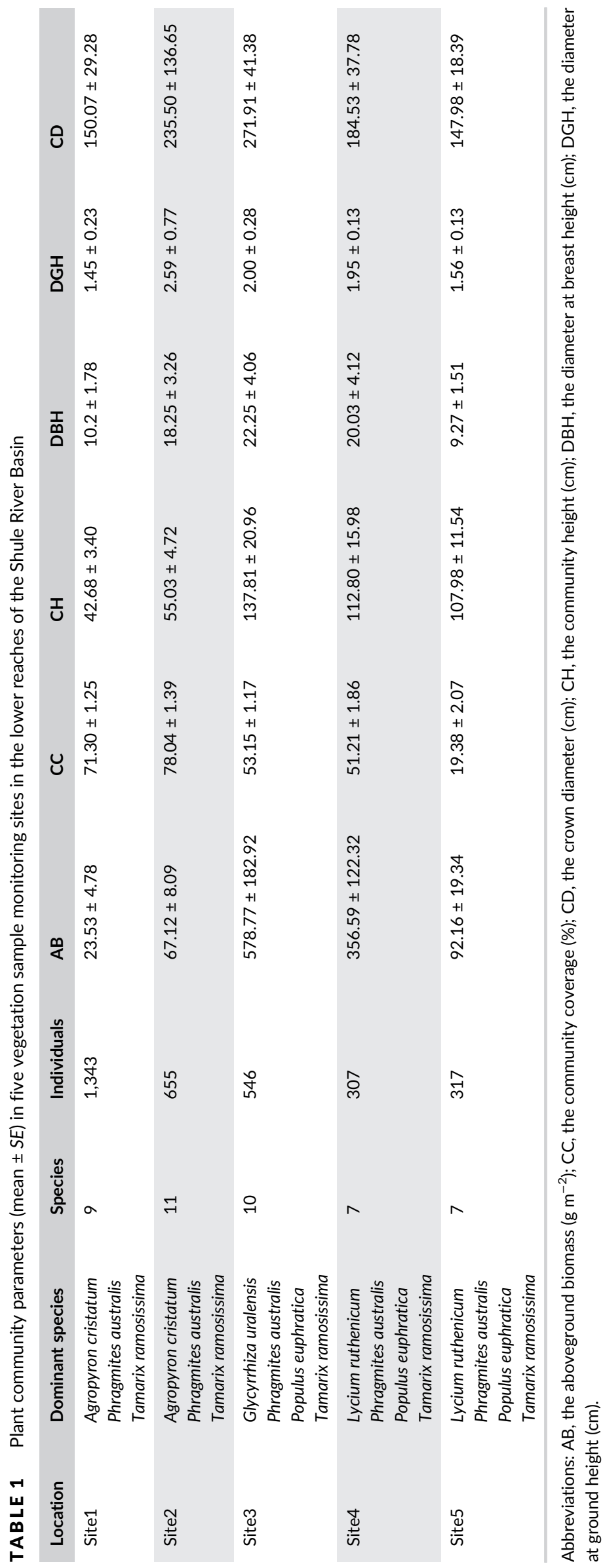


developed by Dong, Li, Wan, and Lin (2012, 2013). Moreover, the location or environment in which the model was built (downstream of the Tarim River) and species were consistent with our study, so it is considered feasible to use this model for our study. In particular, for Populus euphratica and Tamarix ramosissima we calculated their biomass, $B_{p}$ and $B_{t}(\mathrm{~kg})$ respectively, according to

$$
\begin{aligned}
B_{p} & =\rho_{v} 0.000050156 D^{2.08997} H^{0.741585}+0.016 A^{2}+2.291 A \\
& +11.084\left(R^{2}=.87\right), B_{t}=0.074\left(P^{2} H\right)^{1.033}\left(R^{2}=.816\right)
\end{aligned}
$$

where $H$ is the height $(\mathrm{m}), D$ the diameter at breast height $(\mathrm{cm}), \rho_{v}$ the average volume density of trunk of Populus euphratica $\left(748.43 \mathrm{~kg} \mathrm{~m}^{-3}\right.$ ), $A$ the crown area $\left(\mathrm{m}^{2}\right)$, and $P$ the perimeter of the crown $(\mathrm{m})$. In each $1 \times 1 \mathrm{~m}$ quadrat for herbaceous species, we measured the coverage, number, height and biomass of each species. For species with clonal growth, we visually counted each clump as one 'individual' (Cheplick, 1989), with the coverage estimated as an ellipse equation using the length of the longest axis and the length of the axis perpendicular to the longest axis. The green, above-ground stems and leaves were then clipped and sorted by species and dried at $60^{\circ} \mathrm{C}$ for $48 \mathrm{hr}$ and weighed $( \pm 0.01 \mathrm{~g})$ to estimate the biomass of each herbaceous species.

\subsection{Functional trait measurement}

For each species, we chose to measure 10 functional trait from four trait categories (whole-plant level traits, leaf morphology traits, leaf chemical traits and leaf physiological traits), including height, leaf thickness, maximum leaf photosynthesis rate $A_{\max }$, transpiration rate $E$, leaf stomatal conductance $g_{s}$, leaf instantaneous water use efficiency $\mathrm{WUE}_{i}$, leaf dry mass content LDMC, specific leaf area SLA, leaf nitrogen content LNC and leaf phosphorus content LPC. They were measured according to the protocol described by Perez-Harguindeguy et al. (2013) and Zhou, Guo, Zhang, and Du (2018). We measured these 10 functional traits in 2017 and 2018 for mature individauls of eight dominant species, listed in Table 1, including five dominant herbaceous species and only three species found of trees/shrubs. These eight species accounted for more than $90 \%$ of the total abundance of all species (Figure S3). The leaf gas exchange rate was measured from randomly sampled 15 fully developed and undamaged leaves per species from eight plants per site. The measurements were conducted between 9:30 a.m. and 12:00 a.m. during sunny clear days from August 15th to 21st using a GSF-3000 portable photosynthesis system (GFS-3000, Heinz Walz, Germany). The measurements were taken at a constant leaf temperature of $24^{\circ} \mathrm{C}$ and Photosynthetic active radiation of $1,800 \mu \mathrm{mol} \mathrm{m}{ }^{-2} \mathrm{~s}^{-1}$, which was set based on the average light intensity during the measurement. The concentration of $\mathrm{CO}_{2}$ in the environment is $400 \mathrm{ppm}$. As the net photosynthetic data normally tends to stabilize after the leaves have been placed in the leaf chamber for 2 min ( $\mathrm{Li}$ et al., 2016), we started the measurement after the first 2 min. We took another 15 fully developed and undamaged leaves per species from eight plants per site. We weighted the fresh leaf, measured its thickness, scanned at $300 \mathrm{dpi}$ (EPSON V370, Seiko Epson Corporation, Japan), then dried at $80^{\circ} \mathrm{C}$ for $48 \mathrm{hr}$, and reweighed using a balance $\left( \pm 10^{-4} \mathrm{~g}, \mathrm{BSA} 224 \mathrm{~S}-\mathrm{CW}\right.$, Sartorius, Germany). The leaf area was calcualted from the scanned images using ImageJ software (Rueden et al., 2017). We then collected these dried leaves of each species and measured $\mathrm{N}$ and $\mathrm{P}$ concentrations using an Automatic Discrete Analyzer (SmartChem 200, Italy). Together, for each leaf, we calculated the leaf area $\left(\mathrm{cm}^{2}\right)$, leaf thickness $(\mathrm{mm})$, leaf photosynthetic rate $\left(\mu \mathrm{mol} \mathrm{m} \mathrm{m}^{-2} \mathrm{~s}^{-1}\right)$, leaf stomatal conductance ( $\mathrm{mol} \mathrm{m}^{-2} \mathrm{~s}^{-1}$ ), leaf instantaneous water use efficiency $\left(\mathrm{WUE}_{i}=\right.$ leaf photosynthetic rate/transpiration rate, $\left.\mu \mathrm{mol} \mathrm{mol}{ }^{-1}\right)$, specific leaf area (SLA $=$ area/dry weight, $\mathrm{m}^{2} \mathrm{~g}^{-1}$ ), leaf dry mass content (LDMC = dry weight/fresh weight, \%), leaf nitrogen content $\left(\mathrm{g} \mathrm{kg}^{-1}\right)$ and leaf phosphorus content $\left(\mathrm{g} \mathrm{kg}^{-1}\right)$.

\subsection{Soil profile sampling and measurement}

We collected 54 soil samples per site using a cutting ring (volume of $100 \mathrm{~cm}^{3}$ ) from the surface to $1 \mathrm{~m}$ depth and divided each sample into six layers $(0-5,5-20,20-40,40-60,60-80,80-100 \mathrm{~cm})$. The samples were air-dried and passed through a $2 \mathrm{~mm}$ sieve before laboratory analysis (Carmo \& Jacobi, 2016). For each layer of each sample, we measured seven key chemical and physical variables, including indicators associated with nutrient-impoverished soils: soil organic carbon (SOC), soil total nitrogen (STN), soil total phosphorus (STP), total dissolved salts (TDS), soil moisture content (SMC), soil bulk density (SDB) and soil $\mathrm{pH}$. Samples were processed and analyzed at the College of Earth and Environment Sciences and Analysis and Testing Center (Lanzhou University). The $N$ and $P$ concentrations in the soil were measured using an Automatic Discrete Analyzer (SmartChem 200, Italy); and C concentration using the Walkley-Black method (organic matter oxidation with $\mathrm{K}_{2} \mathrm{Cr}_{2} \mathrm{O}_{7}$; Sherrod, Dunn, Peterson, \& Kolberg, 2002). Four salt cations $\left(\mathrm{K}^{+}\right.$, $\mathrm{Na}^{+}, \mathrm{Ca}_{2}{ }^{+}$and $\left.\mathrm{Mg}_{2}{ }^{+}\right)$and two anions $\left(\mathrm{Cl}^{-}\right.$and $\left.\mathrm{SO}_{4}{ }^{2-}\right)$ in soil were determined by ion chromatograph (ICS-1500, Dionex, America), and $\mathrm{HCO}_{3}{ }^{-}$and $\mathrm{CO}_{3}{ }^{2-}$ by the acid titration method (Xing, Kang, \& $\mathrm{Ma}, 2017)$. TDS were measured as the summation of the anions and cations. SMC was determined by oven drying at $105^{\circ} \mathrm{C}$ for more than $12 \mathrm{hr}$ and then calculated as ([wet soil-dry soil]/dry soil $\times 100$, \%). The value of $\mathrm{pH}$ was measured with an acidity meter (PHS-3C, Rex, China) in a 1:2.5 soil:water soluton.

\subsection{Data analysis}

All analyses were performed in R 3.5.2 ( $R$ Development Core Team, 2017).

We analyzed the funcitonal traits at the site level (each site has a different level of groundwater depth and thus is considered as a community). CWM values are defined as the sum of the mean trait value of each species weighted by its abundance (or biomass) in a given 
TAB LE 2 Summary of Kruskal-Wallis one-way ANOVA for the effects of groundwater depth on community-level weighted mean (CWM) traits of tree/shrub and herb

\begin{tabular}{|c|c|c|c|c|c|}
\hline Group & CWM traits & \multicolumn{2}{|c|}{ Tree/shrub } & \multicolumn{2}{|l|}{ Herb } \\
\hline Whole plant & Height & 13.632 & .009 & 63.374 & $<.001$ \\
\hline \multirow[t]{3}{*}{ Morphology } & LDMC & 31.963 & $<.001$ & 23.579 & $<.001$ \\
\hline & SLA & 45.711 & $<.001$ & 81.907 & $<.001$ \\
\hline & Leaf thickness & 17.61 & .001 & 80.348 & $<.001$ \\
\hline Chemical & Leaf $P$ & 19.485 & $<.001$ & 12.517 & .014 \\
\hline \multirow[t]{3}{*}{ Physiological } & $A_{\max }$ & 44.636 & $<.001$ & 89.653 & $<.001$ \\
\hline & $g_{s}$ & 15.938 & .003 & 72.256 & $<.001$ \\
\hline & $E$ & 47.022 & $<.001$ & 64.682 & $<.001$ \\
\hline
\end{tabular}

Abbreviations: $A_{\max }$, maximum leaf photosynthesis rate; $E$, transpiration rate; $g_{s}$, leaf stomatal conductance; LDMC, leaf dry mass content; LNC, leaf nitrogen content; LPC, leaf phosphorus content; SLA, specific leaf area; $W_{U} E_{i}$, leaf instantaneous water use efficiency.

Significant results $(p<.05)$ are in bold.

community and have been widely used to assess the shifts in functional composition (Garnier et al., 2004). In particular, we calculated CWMs of height, leaf thickness, $A_{\max }, E, g_{s}, W_{i}$, LDMC, SLA, LNC and LPC for each site as, CWM $=\sum_{i=1}^{n}\left(P_{i} \times\right.$ trait $\left._{i}\right)$, where $P_{i}$ and trait are, respectively, the relative abundance and the mean trait value of species $i$ in a site. The relative abundance of each species in each quadrat, $P_{i}$, was calculated as the abundance of a given species divided by the total abundance of all species. A Kruskal-Wallis one-way ANOVA was used to detect the differences in CWMs at different groundwater depths (sites), and a Wilcoxon signed rank test was used for post hoc comparison. Note that for trees/shrubs and herbs we calculated their CWMs separately. All variables were tested for normality and homogeneity of variance using the Shapiro-Wilk test and Levene's test.

We used nine environmental variables related to vegetation growth (eight soil variables and one topographic variable [groundwater depth]) and a regression model to determine the relationship between soil properties and groundwater depth. The eight soil variables included six chemical variables (SOC, STN, STP, TDS, $\mathrm{pH}$ and $\mathrm{C} / \mathrm{N}$ ), and two physical variable (SMC and SBD). In particular, we used the stepwise regression based on the Akaike information criterion (AIC) method to establish the relationship between main community parameters (i.e., community height, species abundance, aboveground biomass and community coverage) and these nine environmental variables. Note, SMC was included as averages for two layers (0-40 and $40-100 \mathrm{~cm}$ ); other soil variables were averaged across $0-40 \mathrm{~cm}$ soil depth. This is because the root activity of the herbaceous community is shallow, with the nutrient utilization and the hydraulic lift of trees/shrubs (causing the accumulation of topsoil nutrients) the highest only in the topsoil (Prieto, Armas, \& Pugnaire, 2012; Zhang et al., 2018). In contrast, trees/shrubs and herbs have different water use efficiency for shallow versus deep soil water (Cui, Ma, Feng, Sun, \& Sun, 2017).
The plant community in each site (with a particular groundwater depth) was described using a redundancy analysis (RDA) to identify key environmental variables that drive species distribution. Before analysis, we used the decostand() function to perform a Hellinger transformation on the species data (Legendre \& Gallagher, 2001). We also performed a collinearity test on the environmental variables using the variance inflation factors (VIF) to remove the collinearity variables (VIF > 10) before the RDA analysis. The model performance was expressed by the corrected $R$ squared $\left(R_{\mathrm{adj}}{ }^{2}\right)$ using the Ezekiel formula (Ezekiel, 1942). Among these nine environmental variables, we also considered the contributions of eight ions $\left(\mathrm{K}^{+}, \mathrm{Na}^{+}, \mathrm{Ca}_{2}{ }^{+}, \mathrm{Mg}_{2}{ }^{+}, \mathrm{Cl}^{-}, \mathrm{SO}_{4}{ }^{2-}, \mathrm{HCO}_{3}{ }^{-}\right.$and $\left.\mathrm{CO}_{3}{ }^{2-}\right)$ in the soil to species distribution. Forward selection with two stopping criteria (Blanchet, Legendre, \& Borcard, 2008) was used to examine these three sets of independent variables (topography [groundwater depth], chemistry [six soil chemicals and eight ion contents] and physics [SMC and SBD]). We also ran variance decomposition to assess the contribution rate of each independent variable. Each canonical axis is tested using the Monte Carlo permutation test $(9,999$ permutations; Legendre, Oksanen, \& ter Braak, 2011).

\section{$3 \mid$ RESULTS}

The results showed all functional (trees/shrubs and herbs) traits had significant differences between different sites (Table 2), suggesting that functional traits responded to changes in groundwater depth (Figures 2 and 3). For trees/shrubs, SLA ${ }_{C W M}$ decreased with increasing groundwater depth $(p<.05$, Figure 2a) and dropped sharply at Site4 (groundwater depth: $4.04 \mathrm{~m}$ ). LDMC $_{\mathrm{CWM}}$ was much higher at Site5 (groundwater depth: $5.42 \mathrm{~m}$ ), different from the values of other four sites $(p<.05$, Figure $2 b) . A_{\max c w m}$ was different among sites $(p<.05$, Figure 2c) and showed a tendency to increase first and then decrease from Site1 to Site5. The $g_{\mathrm{scw}}$ at Site5 was significantly 

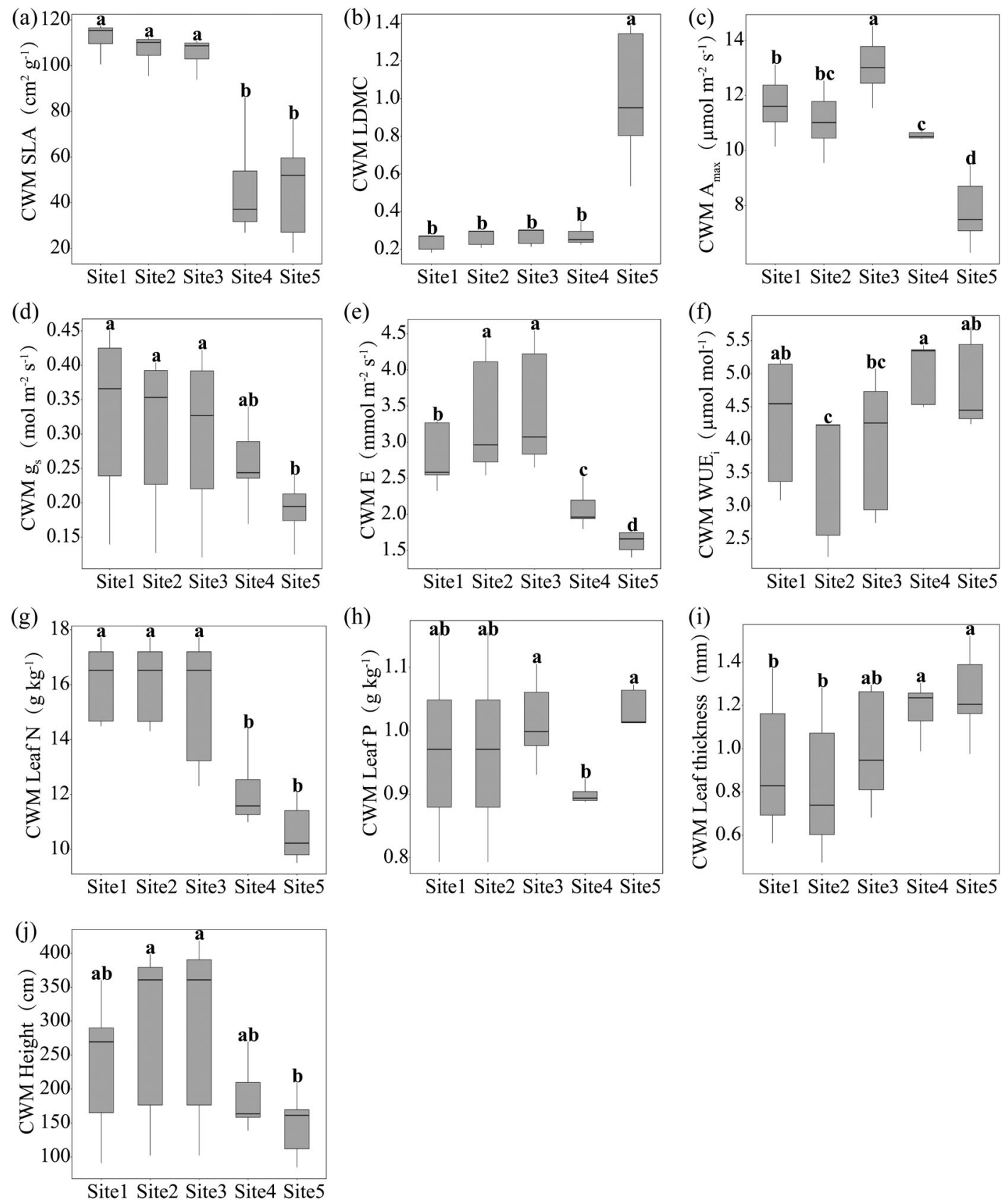

FIGURE 2 The effects of groundwater depth change on community-level weighted means (CWM) of functional traits of tree/shrub. (a) Specific leaf area; (b) leaf dry mass content; (c) maximum leaf photosynthesis rate; (d) stomatal conductance; (e) transpiration rate; (f) instantaneous water use efficiency; (g) leaf nitrogen content; (h) leaf phosphorus content; (i) leaf thickness; and (j) height. Different lowercase letters indicate significant differences (Tukey's test, $p<.05$ ) for each site

different from the values of other sites $(p<.05$, Figure $2 \mathrm{~d})$; except for Site4. $E_{C W M}$ increased first and then decreased with increasing groundwater depth $(p<.05$, Figure $2 \mathrm{e})$. WUE $\mathrm{E}_{\mathrm{i} W \mathrm{M}}$ differed significantly among sites ( $p<.05$, Figure $2 \mathrm{f}$ ), increasing with groundwater depth except for Site1 (groundwater depth: $1.07 \mathrm{~m}$ ). Leaf $N_{\mathrm{CWM}}$ remained stable with increasing groundwater depth, but decreased significantly at Site 4 and Site $5\left(p<.05\right.$, Figure $2 \mathrm{~g}$ ). The thickness $\mathrm{CWM}_{\mathrm{C}}$ became significantly higher after Site3 (groundwater depth: $2.78 \mathrm{~m}$ ) with the depth of the groundwater significantly increased $(p<.05$, Figure $2 \mathrm{i})$. Height ${ }_{\mathrm{CWM}}$ showed a quadratic function with the increase of groundwater depth, with the highest value appeard in Site3, and differed between Site 3 and Site 5 ( $p<.05$, Figure 2j). For herbs, with the increase of groundwater depth, SLA CWM first showed an increase and followed by a decline, with significant differences among the five sites $(p<.05$, Figure 3a) and a maximum at Site3. The results of the ${ }_{\text {LDMC }}$ CWM showed significant differences between the values of Site1 and the other four sites, but there was no significant difference between the four sites $(p<.05$, Figure $3 b) . A_{\max C W M}$ and $E_{C W M}$ decreased significantly with the increasing depth of the groundwater $(p<.05$, Figure $3 \mathrm{~b}, \mathrm{e})$, and height $\mathrm{CWM}_{\mathrm{CW}}$ showed the opposite $(p<.05$, 


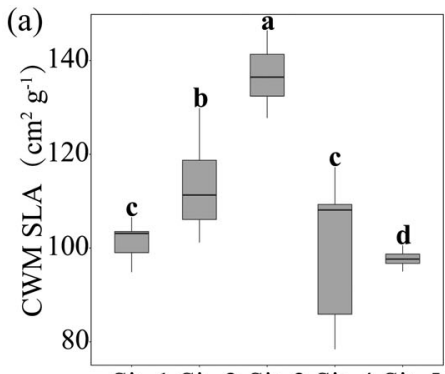

Site1 Site2 Site3 Site4 Site5
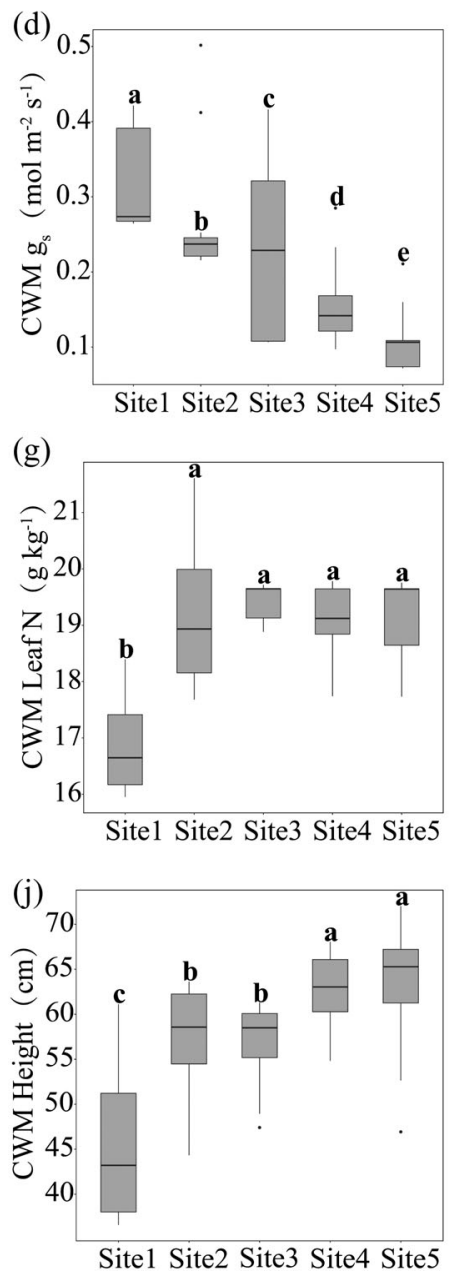

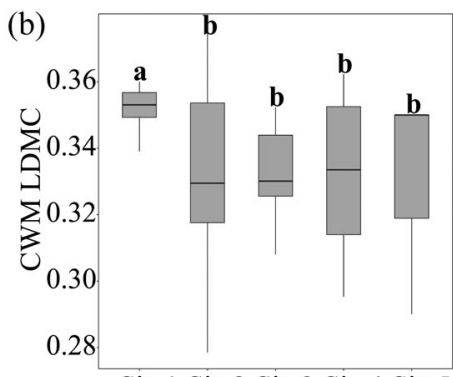

Site1 Site2 Site3 Site4 Site5

(e)

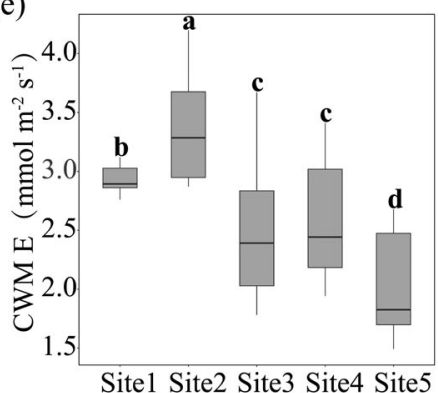

(h)

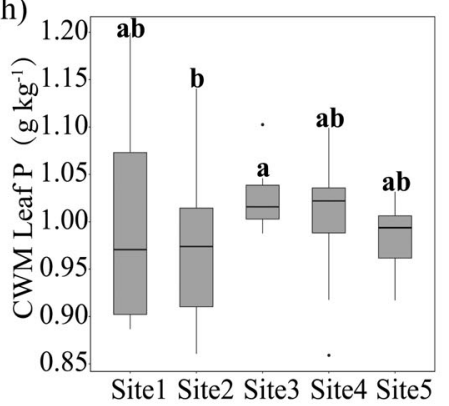

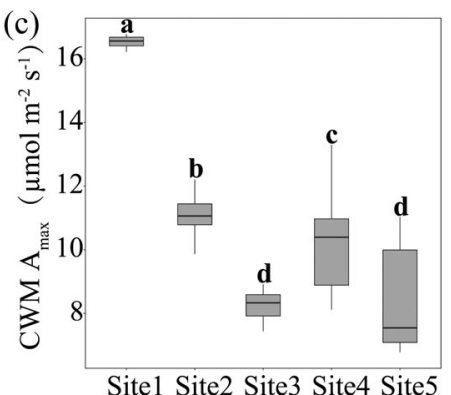

(f)

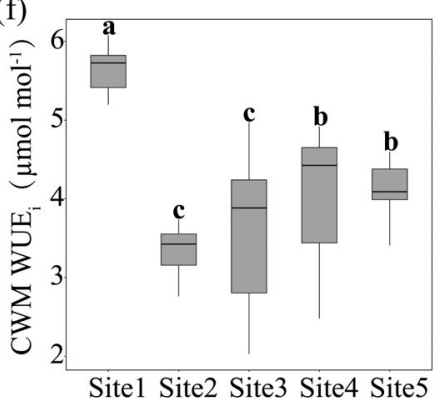

(i)

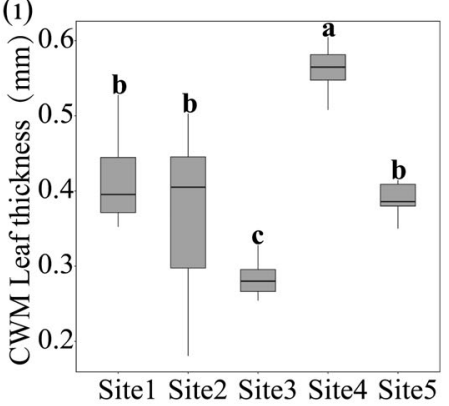

FIGURE 3 The effects of groundwater depth change on community-level weighted means (CWM) of functional traits of herb. (a) Specific leaf area; (b) leaf dry mass content; (c) maximum leaf photosynthesis rate; (d) stomatal conductance; (e) transpiration rate; (f) instantaneous water use efficiency; (g) leaf nitrogen content; (h) leaf phosphorus content; (i) leaf thickness; and (j), height. Different lowercase letters indicate significant differences (Tukey's test, $p<.05$ ) for each site

Figure $3 \mathrm{j})$. The trend of $\mathrm{WUE}_{\mathrm{iCWM}}$ value was consistent with that of trees/shrubs $\left(p<.05\right.$, Figure 3f). Leaf $N_{C W M}$ and leaf $P_{C W M}$ did not change significantly with increasing groundwater depth, except that the leaf $N_{C W M}$ value of Site1 was lower than that of the other sites $(p<.05$, Figure $3 g, h)$. As the depth of the groundwater increases, the thickness $\mathrm{CWM}_{\mathrm{M}}$ decreased first and then increased $(p<.05$, Figure $3 \mathrm{i})$.

With the increase of groundwater depth, STN $(F=48.24, p<.001$, Figure 4a), STP $(F=24.34, p<.001$, Figure $4 b)$ and SOC $(F=35.38$, $p=.003$, Figure $4 c$ ) increased first but then declined. In contrast, SBD
$(F=24.26, p<.001$, Figure $4 \mathrm{~g})$ and soil $\mathrm{pH}(F=11.93, p<.001$, Figure $4 \mathrm{e}$ ) declined first but then increased. SMC in 40-100 cm layer $(F=53.34, p<.001$, Figure $4 \mathrm{i})$ and soil $\mathrm{C} / \mathrm{N}(F=19.27, p<.001$, Figure $4 d$ ) decreased with increasing groundwater depth. Similarly, $\mathrm{SMC}$ at the layer of $0-40 \mathrm{~cm}$ showed the same trend as the layer of $40-100 \mathrm{~cm}$ with the groundwater depth ( $F=29.2, p<.001$, Figure $4 \mathrm{~h})$. The TDS increased first but then decreased with groundwater depth ( $F=35.06, p<.001$, Figure $4 f)$. Results from the eight variables of ions in the soil is shown in Table S1. 

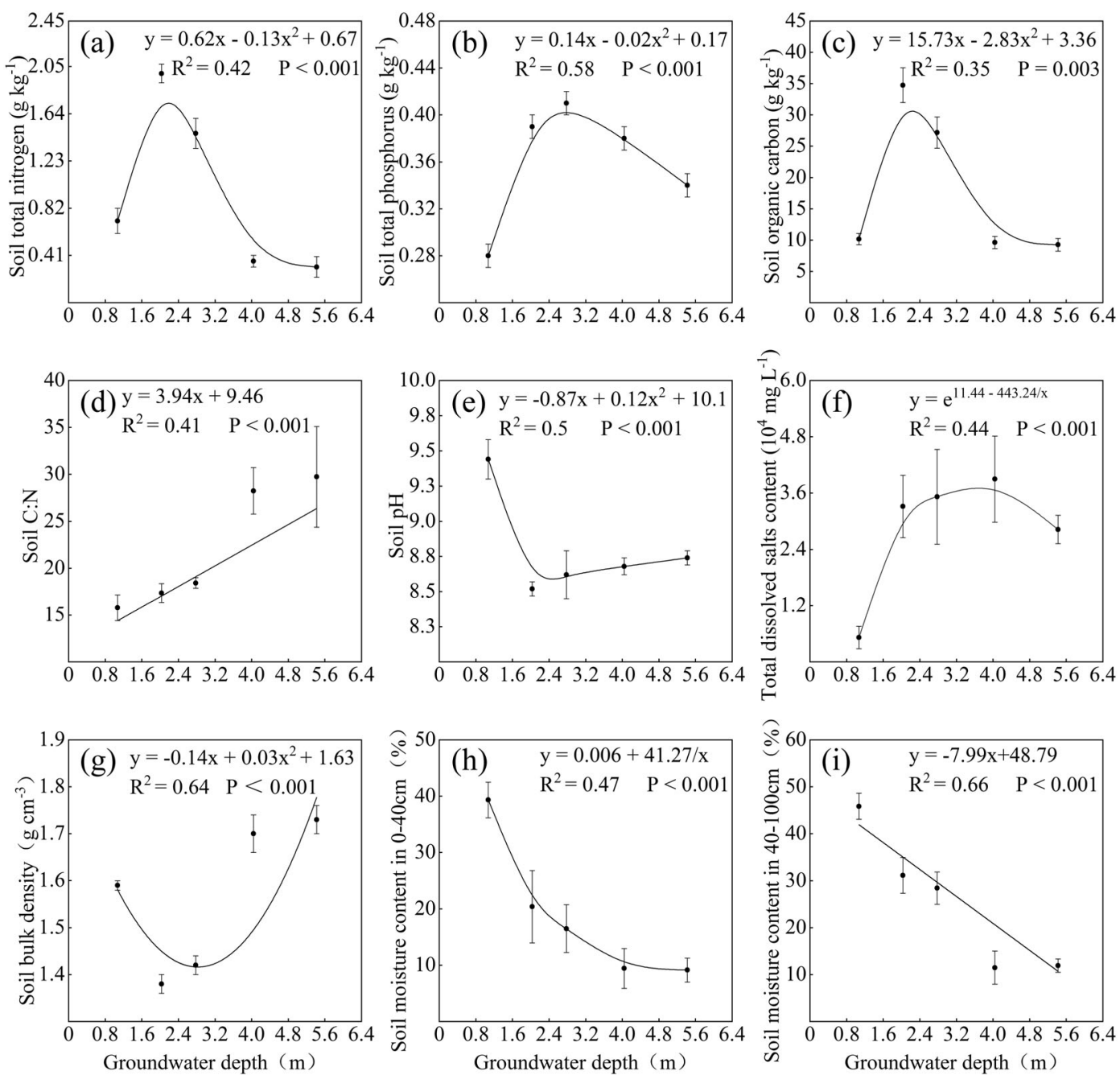

FIGURE 4 The effects of groundwater depth on soil properties. (a) Soil total nitrogen content; (b) soil total phosphorus content; (c) soil organic carbon content; (d) soil carbon to nitrogen ratio; (e) soil pH; (f) total dissolved salt content; (g) soil bulk density; (h) soil moisture content $(0-40 \mathrm{~cm})$; and (i) soil moisture content $(40-100 \mathrm{~cm})$

Soil properties and groundwater depth have had significant effects on community height, species abundance, aboveground biomass and community cover (Table 3 ). In the forward selection of the permutation test $(p<.05)$, the groundwater depth, soil $\mathrm{K}^{+}$and STN passed the test (Table 4). Variance decomposition as shown in the Venn diagram (Figure 5) suggests that the three environmental variables (including their interactions) can explain a total of $41.7 \%$ of vegetation variation. The groundwater depth contributed the highest (21.16\%), followed by soil $\mathrm{K}^{+}(9.94 \%)$ and the STN $(4.9 \%)$. The RDA explained $33.66 \%$ variation of tree/shrub species distributions (contains nine variables after removing others due to collinearity) and $32.15 \%$ variation of herbaceous species distributions (contains 10 variables after removing others due to collinearity). The first two axes explained a total of $33.14 \%$ of the variation of tree/shrub species distributions, of which the first axis explained $26.47 \%$, and the second $6.67 \%$ (Figure 6a). The first two axes explained a total of $28.39 \%$ of the variation of herbaceous species distributions, of which the first axis explained $18.19 \%$, and the second $10.2 \%$ (Figure $6 \mathrm{~b}$ ).

\section{DISCUSSION}

\subsection{Impact of groundwater depth on plant functional traits}

Previous studies have revealed that at the community level, leaf trait values can be indicative of how plants respond to environmental changes (Fajardo \& Piper, 2011; Li et al., 2016), such as water stress, which may result in reduced leaf area and decreased stomatal conductance. The extent of adaptation of these traits depends on the availability of local water resources and nutrients and varies among species. In general, trees/shrubs in arid areas are more advantageous

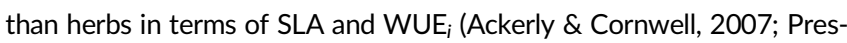
ton, Cornwell, \& DeNoyer, 2006). Our results indicate that changes in morphological traits (Table 2) of trees/shrubs, compared to those of herbs, show a more pronounced adaptation to arid environments (Figures 2a,b,i and 3a,b,i). In particular, the SLA ${ }_{C W M}$ of trees/shrubs gradually decreases with the increase of groundwater depth, and the 
$\mathrm{SLA}_{C W M}$ value of trees/shrubs becomes much lower than that of herbs. This shows that changes in environmental factors in arid areas (especially the depth of groundwater) have varying degrees of impact on functional traits at the plant community level. Differences in plant functional traits, such as nutrient utilization and storage strategies, can affect their habitat requirements and thus tolerance to arid environments (Cadotte, Carscadden, \& Mirotchnick, 2011; Reich, 2014). The habitats in arid areas are mostly characterized by drought, salinization and nutritional deficiencies. Groundwater is the only source of water and, therefore, a key environmental factor of plant functional traits. In general, SLA and LDMC are two closely related functional traits and normally respond oppositely to changes in groundwater depth. The response of $\mathrm{LDMC}_{\mathrm{CWM}}$, SLA $\mathrm{CWM}_{\mathrm{CW}}$ and leaf thickness $\mathrm{CWM}_{\mathrm{M}}$ to changes in groundwater depth reflects the alternative strategies of plant communities in coping with environmental stress (Wright, Reich, \& Westoby, 2001).

Plant photosynthesis, transpiration and water use efficiency are key control processes for ecosystem carbon and water cycles (Jiang, Tang, Yu, Dong, \& Zhang, 1999; van der Molen et al., 2011). The trend of the values of the physiological traits of trees/ shrubs and herbs (Table 2) is consistent at the community level. Similarly, the values of $g_{\mathrm{s} C W M}, E_{\mathrm{CWM}}$ and $A_{\max \mathrm{CWM}}$ decrease with increasing groundwater depth, while $W_{U E} E_{i c W M}$ showed an opposite response (Figures 2c,d,e,f and 3c,d,e,f), reflecting adaptation of leaf physiological traits to arid environment at the community

TABLE 3 Summary of the multiple stepwise regressions between community characteristics and environmental variable

\begin{tabular}{|c|c|c|}
\hline Regression model & $R^{2}$ & $p$ \\
\hline $\begin{array}{l}\text { Community height }=-55.592 \text { Soil pH } \\
-140.456 \text { STN }-887.763 \text { SBD } \\
+42.123 \text { Groundwater depth }-0.002 \\
\text { TDS }+2033.386\end{array}$ & .67 & .012 \\
\hline $\begin{array}{l}\text { Species abundance }=11.875 \text { SWC100 } \\
-50.622 \text { STP }-1.481 \text { Groundwater } \\
\text { depth }+28.1\end{array}$ & .95 & $<.001$ \\
\hline $\begin{array}{l}\text { Aboveground biomass }=40.379 \mathrm{C} / \mathrm{N} \\
-3470.14 \mathrm{SBD}-0.034 \mathrm{TDS}-3,029.83 \\
\mathrm{SMC} 100+6,385.956\end{array}$ & .62 & .004 \\
\hline $\begin{array}{l}\text { Community coverage }=-7.557 \\
\text { Groundwater depth }+6.56 \mathrm{~S} \mathrm{TN} \\
+71.082\end{array}$ & .7 & $<.001$ \\
\hline
\end{tabular}

Abbreviations: $\mathrm{C} / \mathrm{N}$, the soil organic carbon/soil total nitrogen; SBD, the soil bulk density $\left(\mathrm{g} \mathrm{cm}^{-3}\right)$; SMC100, the soil moisture content in 40-100 cm (\%); SOC, the soil organic carbon $\left(\mathrm{g} \mathrm{kg}^{-1}\right)$; STN, the soil total nitrogen $\left(\mathrm{g} \mathrm{kg}^{-1}\right)$; STP, the soil total phosphorus $\left(\mathrm{g} \mathrm{kg}^{-1}\right)$; TDS, the total dissolved salts content $\left(\mathrm{mg} \mathrm{L}^{-1}\right)$. level (Cunningham, Summerhayes, \& Westoby, 1999; Wright et al., 2001).

Leaf $N$ and $P$ belong to the biochemical structural characteristics of the leaf. They can reflect the response of individual or population of plants to environmental changes, but they are not completely dependent on the environment (i.e., plants growing in barren places have higher nutrient preservation rates; Michaels, 2003; Wright et al., 2004). We found that only the $\mathrm{LNC}_{\mathrm{CWM}}$ of trees/shrubs showed a large change in Site4 (groundwater depth: $4.04 \mathrm{~m}$ ), which is the same as the trend of SLA $A_{C W M}$, indicating that it is also affected by the leaf shape adaptation strategy. This is also reflected in the whole plant traits (height) of trees/shrubs and herbs. In other words, the $N$ and $P$ nutrition in the arid region is extremely scarce (Table 5), and the $N$ and $P$ contents of the plant are maintained at only the minimum amount for survival. This may be a survival strategy for plants in the arid region to cope with the barren environment. In summary, leaf biochemical and morphological traits are particularly important in revealing the adaptation of vegetation to resource competition and arid environment at the community level, especially with SLA, LDMC, height, $A_{\max }$ and $\mathrm{WUE}_{i}$ sensitive to the drought limitation.

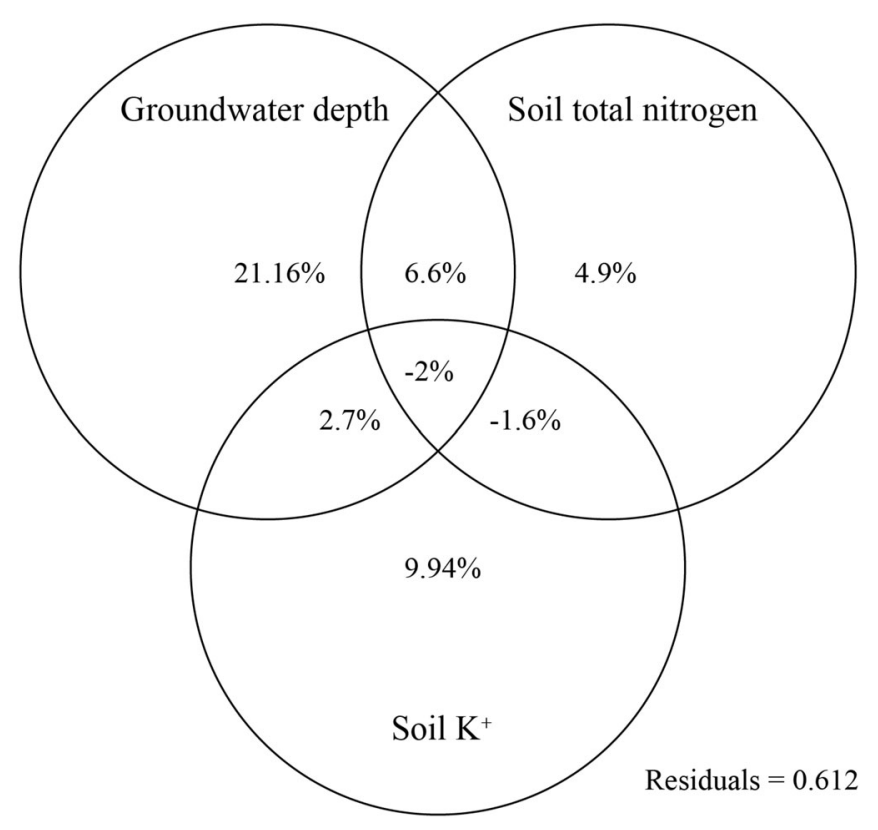

FIGURE 5 Venn diagram of variance decomposition and interaction of groundwater depth, soil $\mathrm{K}^{+}$and soil total nitrogen content in explaining the variation of vegetation distribution. Number indicates the percentage of grouping variables that are interpreted and co-interpreted separately. The three variables jointly explained $41.7 \%$ of the variation in vegetation distribution

\begin{tabular}{lllll} 
Parameter & Variance decomposition (\%) & $\boldsymbol{F}$ & $\boldsymbol{p}$ & $\boldsymbol{R}_{\text {adj }}{ }^{2}$ \\
\hline Groundwater depth & 21.16 & 11.45 & .001 & .26 \\
\hline Soil K & 9.94 & 4.59 & .001 & .35 \\
\hline Soil total nitrogen & 4.9 & 2.72 & .023 & .39 \\
\hline
\end{tabular}

TABLE 4 The contribution of the forward selection explanatory variables with two stopping criteria to the species distribution, from the variance decomposition 

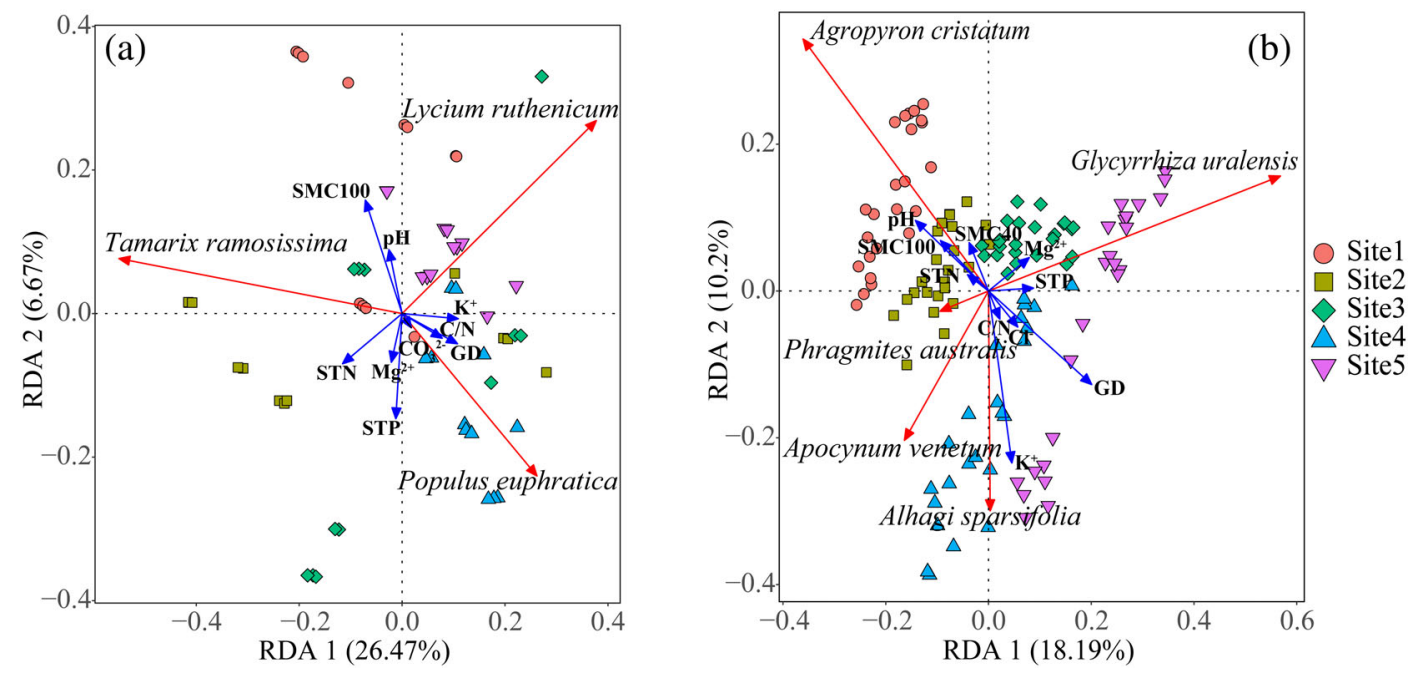

FIGURE 6 Redundancy analysis of environmental variables and 180 vegetation quadrat data (species abundance) from five vegetation sample monitoring areas in the lower reaches of the Shule River Basin, northwestern China. (a) Results of 60 tree/shrub quadrats; (b) results of 120 herbal quadrats. Codes as in Tables 1 and 5 [Colour figure can be viewed at wileyonlinelibrary.com]

\section{2 | Impact of groundwater depth change on soil properties}

Previous studies on the relationship between groundwater and soil in arid regions have revealed that soil properties (physical or chemical) are strongly influenced by groundwater depth changes (Álvarez-Rogel, Carrasco, Marín, \& Martínez-Sánchez, 2007; Zhou et al., 2010). Soil moisture is generally the limiting factor for species growth in arid regions (Keiffer \& Ungar, 1997; Veldkornet, Potts, \& Adams, 2016), and the variation of soil moisture content is mainly determined by groundwater depth (Bornman, Adams, \& Bate, 2008). Our research indicates that SMC decreases significantly with increasing groundwater depth (Figure 4h,i, Table 5), which is consistent with many other studies in the Tarim and Hei rivers (Chen et al., 2008; Zhang et al., 2018). Our results also show that SMC is more strongly affected by groundwater depth changes at the bottom layer $(40-100 \mathrm{~cm})$ compared to the surface layer $(0-40 \mathrm{~cm})$. SBD is related to plant root penetration, porosity and gas exchanges (Costantini et al., 2016), while excessive bulk density will reduce soil water holding capacity and lead to drought stress (Stirzaker, Passioura, \& Wilms, 1996). Previous studies have shown that SBD increases with increasing groundwater depth (Zhang et al., 2018), as is the trend with our results (Figure 4g, Table 5).

Previous studies have also pointed out that in the extremely arid regions, the availability of soil nutrients due to root hydraulic lift is mainly concentrated on the soil surface (Prieto et al., 2012). Therefore, the change of nutrients in the soil may be resulted from the interaction of groundwater and vegetation. The difference between our findings and the previous one is that we found that SOC, STN and STP (Figure 4a,b,c, Table 5) increased first and then decreased with deepening of the groundwater, which may be related to the highest vegetation coverage at particular sites (Rao \& Pathak, 1996). This also affects the TDS and soil pH (Figure 4e,f, Table 5). Low community cover and high evaporation increased the salt accumulation in the soil surface, while the desalting exchange and the alkalization process resulted in lower TDS and higher soil $\mathrm{pH}$. We noted that soil nutrient values (e.g., SOC, STN and STP) at Site1 (groundwater depth: $1.07 \mathrm{~m}$ ) were lower relative to other sites. This is because the vegetation composition in Site1 was mainly herbaceous, and the results obtained are consistent with the "fertile island" effect; that is, in arid and semi-arid regions, due to a series of physical and biological processes, the soil under the trees/shrubs has higher soil nutrient content (Xu, Liu, Yang, Tang, \& Blank, 2012). The appropriate ratio of carbon to nitrogen contributes to the decomposition of microbial fermentation (Costantini et al., 2016). The previous studies suggest that warming and drought can increase $\mathrm{C} / \mathrm{N}$ ratios in temperate-dry terrestrial ecosystems (Sardans, Rivas-Ubach, \& Penuelas, 2012), which is consistent with our results (Figure $4 \mathrm{~d}$, Table 5). That is to say, the place with the most nutrient enrichment may be the most suitable groundwater depth for vegetation growth.

\section{3 | Relationships among groundwater, species and soil properties}

Variations in plant distributions depend on changes in soil properties and groundwater conditions (Gonzalez-Alcaraz, Jimenez-Carceles, Alvarez, \& Alvarez-Rogel, 2014). The results showed that the groundwater depth explained $21.16 \%$ of the variance of vegetation distribution in the forward selection of all environmental variables, greater than the contributions of soil $\mathrm{K}^{+}(9.94 \%)$ and STN $(4.9 \%$; Figure 5 , Table 4). This also shows that groundwater is the main driving force for vegetation distribution in extremely arid regions. Although the individual interpretations of each variable were not high, the total variance explained by selected variables has reached $41.7 \%$ under the interaction of the three environmental variables. This shows that the soil, vegetation and groundwater in the extremely arid regions have 


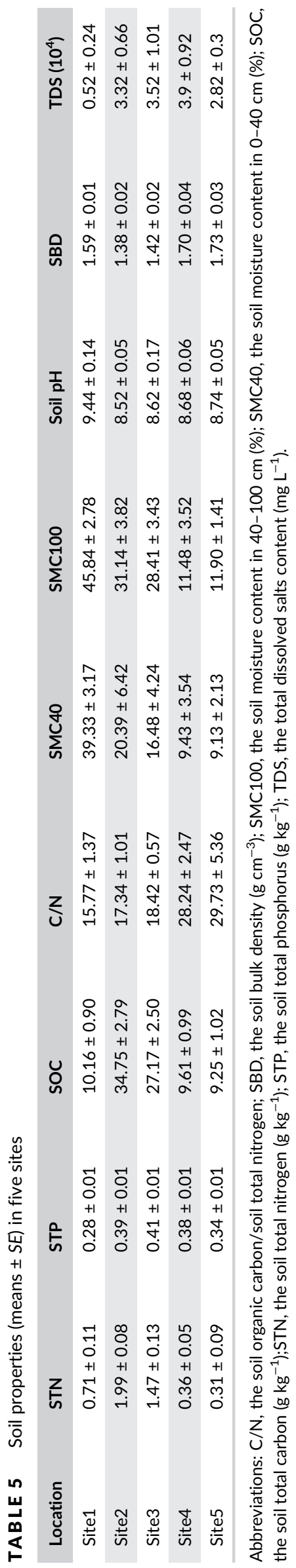

complex interrelationships. Our results indicate that groundwater depth, soil $\mathrm{K}^{+}$and STN play a major role in all other environmental variables, which provide vegetation with the water and nutrients needed for growth (Costantini et al., 2016).

The results of redundant analysis (RDA) also showed that Agropyron cristatum was mainly distributed in places with shallow groundwater depth, high SMC, high soil pH and high STN. The distribution of the other species is more in places with higher groundwater depth, especially Populus euphratica and Alhagi sparsifolia, showing high drought resistance and stronger salt tolerance (Figure $6 a, b$ ). This is also related to the long-rooted, multicellular glandular and salt-reducing physiological structures of these species (Gupta \& Huang, 2014). In our study area, the composition of soil salt ions is mainly $\mathrm{Na}^{+}, \mathrm{Cl}^{-}$and $\mathrm{SO}_{4}{ }^{2-}$, operating at much higher levels than other ions (Table S1). Some studies have also pointed out that the adaptation of vegetation to salinity is usually to control the absorption of $\mathrm{Na}^{+}$and $\mathrm{Cl}^{-}$(Gupta \& Huang, 2014; Munns, 2002; Tester \& Davenport, 2003). Salinity can directly affect nutrient uptake, such as excessive $\mathrm{Na}^{+}$in soil that can reduce the uptake of $\mathrm{K}^{+}$. As $\mathrm{K}^{+}$is essential for various physiological processes in higher plants, it plays an important role in stomatal movement and maintenance of cationic anion ratio (Rajput et al., 2016). Maintaining adequate $\mathrm{K}^{+}$levels is a necessary condition for plants to survive in saline soils. In short, our results show that the change of groundwater depth will cause changes in soil structure and nutrients (Table 5, Figure 4), and also play a major role in the accumulation of soil salinity (eluviation of sites with shallower groundwater depth is stronger), which will affect the growth and distribution of vegetation.

Previous studies have indicated that vegetation cover and community composition can change soil chemistry and contribute to nutrient input and circulation (Rao \& Pathak, 1996; Ross, 1993). For example, studies have shown that with the increase of vegetation coverage, soil nutrients will also increase and the composition of soil particles in the topsoil layer changes significantly, mainly manifested by the decline of sand content and the increase of silt and clay content (Pei, Fu, \& Wan, 2008). Our results also indicate that at the community level, changes in water resources can cause changes in soil physical and chemical properties, which in turn change the leaf shape adaptation and nutrient use strategies of the species. For arid regions, due to water and nutrient shortages, species in the community have adopted strategies to improve water and nutrient use to adapt to environmental changes. Of course, there are also opportunists, which have relatively wide niches (e.g., Tamarix ramosissima and Phragmites australis), usually with higher SLAs and leaf $\mathrm{N}$, and can survive on roadsides, salt marshes and more arid areas. Our results have enhanced the understanding of groundwater on community traits, species distribution and soil nutrient changes in arid regions.

\section{5 | CONCLUSIONS}

Here, we studied how groundwater depths affect community-level plant functional traits and soil properties, and how major 
environmental drivers in the desert-wetland ecosystem jointly affect the growths and distributions of desert plants. Our results indicated that the species distributions in our study area were mainly driven by variations in the groundwater depth, followed by soil $\mathrm{K}^{+}$, STN content and the interaction of the three. Overall, with the increase of groundwater depth, most soil properties were found to change from lean to enrichment but eventually to barren (e.g., SOC, STP, STN and TDS), while soil $\mathrm{pH}$ and SBD respond in an opposite way. Soil $\mathrm{C} / \mathrm{N}$ and SMC were found to decline significantly with the increase of groundwater depth, especially the response of SMC from 40 to $100 \mathrm{~cm}$ depth. Community-level functional traits showed different responses for trees/shrubs versus herbs, reflecting differences in their adaptability to environmental stresses. In general, SLA $A_{C W M}, L_{C D C} C_{C W M}, A_{\max C W M}$ and Height ${ }_{C W M}$ are more indicative to environmental changes. Compared to herbs, trees and shrubs show better resilience to environmental changes (groundwater depth and soil properties). In arid areas, groundwater can have profound effects on plant traits and distributions and soil properties. The plasticity of these dominant plant species, especially trees and shrubs, to changes in groundwater depth may mitigate the negative impact of environmental stressors (e.g., the groundwater depletion in the arid regions of northwestern China). Nevertheless, maintaining a reasonable groundwater depth and sufficient soil nutrients is essential for the conservation and restoration of desert vegetation.

\section{ACKNOWLEDGMENTS}

The authors would like to thank the staff of the Dunhuang Xihu National Nature Reserve Administration for providing invaluable field assistance. The study was supported by the National Nature Science Foundation of China (Grant Nos. 41671516 and 41701623); the National Key Research and Development Plan of China (Grant No. 2017YFC1501005). C. H. acknowledges the support from the National Research Foundation (Grant 89967).

\section{ORCID}

Dongxia Yue (D) https://orcid.org/0000-0002-9007-2117

\section{REFERENCES}

Abrams, M. D., \& Mostoller, S. A. (1995). Gas-exchange, leaf structure and nitrogen in contrasting successional tree species growing in open and understory sites during a drought. Tree Physiology, 15, 361-370. https://doi.org/10.1093/treephys/15.6.361

Ackerly, D. D., \& Cornwell, W. K. (2007). A trait-based approach to community assembly: Partitioning of species trait values into within- and among-community components. Ecology Letters, 10, 135-145. https:// doi.org/10.1111/j.1461-0248.2006.01006.x

Álvarez-Rogel, J., Carrasco, L., Marín, C. M., \& Martínez-Sánchez, J. J. (2007). Soils of a dune coastal salt marsh system in relation to groundwater level, micro-topography and vegetation under a semiarid Mediterranean climate in SE Spain. Catena, 69, 111-121. https://doi.org/ 10.1016/j.catena.2006.04.024

Anjum, S. A., Xie, X. Y., Wang, L. C., Saleem, M. F., Man, C., \& Lei, W. (2011). Morphological, physiological and biochemical responses of plants to drought stress. African Journal of Agricultural Research, 6, 2026-2032. https://doi.org/10.5897/AJAR10.027
Barbeta, A., Mejia-Chang, M., Ogaya, R., Voltas, J., Dawson, T. E., \& Penuelas, J. (2015). The combined effects of a long-term experimental drought and an extreme drought on the use of plant-water sources in a Mediterranean forest. Global Change Biology, 21, 1213-1225. https://doi.org/10.1111/gcb.12785

Blanchet, F. G., Legendre, P., \& Borcard, D. (2008). Forward selection of explanatory variables. Ecology, 89, 2623-2632. https://doi.org/10. 1890/07-0986.1

Bornman, T. G., Adams, J. B., \& Bate, G. C. (2008). Environmental factors controlling the vegetation zonation patterns and distribution of vegetation types in the Olifants Estuary, South Africa. South African Journal of Botany, 74, 685-695. https://doi.org/10.1016/j.sajb.2008.05.002

Cadotte, M. W., Carscadden, K., \& Mirotchnick, N. (2011). Beyond species: Functional diversity and the maintenance of ecological processes and services. Journal of Applied Ecology, 48, 1079-1087. https://doi.org/ 10.1111/j.1365-2664.2011.02048.x

Canadell, J., Jackson, R. B., Ehleringer, J. R., Mooney, H. A., Sala, O. E., \& Schulze, E. D. (1996). Maximum rooting depth of vegetation types at the global scale. Oecologia, 108, 583-595. https://doi.org/10.1007/ bf00329030

Carmo, F. F. D., \& Jacobi, C. M. (2016). Diversity and plant trait-soil relationships among rock outcrops in the Brazilian Atlantic Rainforest. Plant and Soil, 403, 7-20. https://doi.org/10.1007/s11104-0152735-7

Carvajal, D. E., Loayza, A. P., Rios, R. S., Gianoli, E., \& Squeo, F. A. (2017). Population variation in drought-resistance strategies in a desert shrub along an aridity gradient: Interplay between phenotypic plasticity and ecotypic differentiation. Perspectives in Plant Ecology, Evolution and Systematics, 29, 12-19. https://doi.org/10.1016/j.ppees.2017.10.001

Castle, S. L., Thomas, B. F., Reager, J. T., Rodell, M., Swenson, S. C., \& Famiglietti, J. S. (2014). Groundwater depletion during drought threatens future water security of the Colorado River Basin. Geophysical Research Letters, 41, 5904-5911. https://doi.org/10.1002/ 2014gl061055

Charles, H., \& Dukes, J. S. (2009). Effects of warming and altered precipitation on plant and nutrient dynamics of a New England salt marsh. Ecological Applications, 19, 1758-1773. https://doi.org/10.1890/080172.1

Chen, Y. P., Chen, Y. N., Xu, C. C., \& Li, W. H. (2016). The effects of groundwater depth on water uptake of Populus euphratica and Tamarix ramosissima in the hyperarid region of northwestern China. Environmental Science and Pollution Research International, 23, 17404-17412. https://doi.org/10.1007/s11356-016-6914-8

Chen, Y. N., Pang, Z. H., Chen, Y. P., Li, W. H., Xu, C. C., Hao, X. M., ... Ye, Z. X. (2008). Response of riparian vegetation to water-table changes in the lower reaches of Tarim River, Xinjiang Uygur, China. Hydrogeology Journal, 16, 1371-1379. https://doi.org/10.1007/ s10040-008-0306-1

Cheplick, G. P. (1989). Nutrient availability, dimorphic seed production, and reproductive allocation in the annual grass Amphicarpum purshii. Canadian Journal of Botany-Revue Canadienne de Botanique, 67, 2514-2521. https://doi.org/10.1139/b89-321

Costantini, E. A. C., Branquinho, C., Nunes, A., Schwilch, G., Stavi, I., Valdecantos, A., \& Zucca, C. (2016). Soil indicators to assess the effectiveness of restoration strategies in dryland ecosystems. Solid Earth, 7, 397-414. https://doi.org/10.5194/se-7-397-2016

Cui, Y. Q., Ma, J. Y., Feng, Q., Sun, J. H., \& Sun, W. (2017). Water sources and water-use efficiency of desert plants in different habitats in Dunhuang, NW China. Ecological Research, 32, 243-258. https://doi. org/10.1007/s11284-017-1433-8

Cunningham, S. A., Summerhayes, B., \& Westoby, M. (1999). Evolutionary divergences in leaf structure and chemistry, comparing rainfall and soil nutrient gradients. Ecological Monographs, 69, 569-588. https://doi. org/10.1890/0012-9615(1999)069[0569:Edilsa]2.0.Co;2 
Dong, D. R., Li, X., Wan, H. M., \& Lin, H. J. (2012). Aboveground biomass estimation of Tamarix ramosissima shrub in the lower reaches of Tarim River. Acta Botanica Boreali-Occidentalia Sinica, 32, 384-390. https:// doi.org/10.3969/j.issn.1000-4025.2012.02.026

Dong, D. R., Li, X., Wan, H. M., \& Lin, H. J. (2013). Aboveground biomass estimation of Populus euphratica in the lower reaches of Tarim River. Journal of Desert Research, 33, 724-730. https://doi.org/10.7522/j. issn.1000-694X.2013.00104

Douma, J. C., Bardin, V., Bartholomeus, R. P., \& van Bodegom, P. M. (2012). Quantifying the functional responses of vegetation to drought and oxygen stress in temperate ecosystems. Functional Ecology, 26 , 1355-1365. https://doi.org/10.1111/j.1365-2435.2012.02054.x

Ezekiel, M. J. B. (1942). Methods of correlation analysis. Revista Mexicana de Sociología, 23, 309. https://doi.org/10.2307/3538352

Fajardo, A., \& Piper, F. I. (2011). Intraspecific trait variation and covariation in a widespread tree species (Nothofagus pumilio) in southern Chile. New Phytologist, 189, 259-271. https://doi.org/10.1111/j.1469-8137. 2010.03468.x

Garnier, E., Cortez, J., Billes, G., Navas, M. L., Roumet, C., Debussche, M., ... Toussaint, J. P. (2004). Plant functional markers capture ecosystem properties during secondary succession. Ecology, 85, 2630-2637. https://doi.org/10.1890/03-0799

Gonzalez-Alcaraz, M. N., Jimenez-Carceles, F. J., Alvarez, Y., \& AlvarezRogel, J. (2014). Gradients of soil salinity and moisture, and plant distribution, in a Mediterranean semiarid saline watershed: A model of soil-plant relationships for contributing to the management. Catena, 115, 150-158. https://doi.org/10.1016/j.catena.2013.11.011

Gupta, B., \& Huang, B. (2014). Mechanism of salinity tolerance in plants: Physiological, biochemical, and molecular characterization. International Journal of Genomics, 2014, 18. https://doi.org/10.1155/2014/ 701596

Holmstrup, M., Sorensen, J. G., Maraldo, K., Schmidt, I. K., Mason, S., Tietema, A., ... Ehlers, B. K. (2012). Increased frequency of drought reduces species richness of enchytraeid communities in both wet and dry heathland soils. Soil Biology \& Biochemistry, 53, 43-49. https://doi. org/10.1016/j.soilbio.2012.05.001

Jiang, G. M., Tang, H. P., Yu, M., Dong, M., \& Zhang, X. S. (1999). Response of photosynthesis of different plant functional types to environmental changes along Northeast China transect. Trees-Structure and Function, 14, 72-82. https://doi.org/10.1007/s004680050211

Keiffer, C. H., \& Ungar, I. A. (1997). The effects of density and salinity on shoot biomass and ion accumulation in five inland halophytic species. Canadian Journal of Botany-Revue Canadienne De Botanique, 75, 96-107. https://doi.org/10.1139/b97-012

Kong, W. J., Sun, O. J. X., Chen, Y. N., Yu, Y., \& Tian, Z. Q. (2010). Patchlevel based vegetation change and environmental drivers in Tarim River drainage area of West China. Landscape Ecology, 25, 1447-1455. https://doi.org/10.1007/s10980-010-9505-y

Krober, W., Plath, I., Heklau, H., \& Bruelheide, H. (2015). Relating stomatal conductance to leaf functional traits. Journal of Visualized Experiments, (104), e52738. https://doi.org/10.3791/52738

Lavorel, S., \& Garnier, E. (2002). Predicting changes in community composition and ecosystem functioning from plant traits: Revisiting the holy grail. Functional Ecology, 16, 545-556. https://doi.org/10.1046/j. 1365-2435.2002.00664.x

Legendre, P., \& Gallagher, E. D. (2001). Ecologically meaningful transformations for ordination of species data. Oecologia, 129, 271-280. https://doi.org/10.1007/s004420100716

Legendre, P., Oksanen, J., \& ter Braak, C. J. F. (2011). Testing the significance of canonical axes in redundancy analysis. Methods in Ecology and Evolution, 2, 269-277. https://doi.org/10.1111/j.2041-210X.2010. 00078.x

Li, H. L., Yu, K. L., Ratajczak, Z., Nippert, J. B., Tondrob, D., Xu, D. H., ... Du, G. Z. (2016). When variability outperforms the mean: Trait plasticity predicts plant cover and biomass in an alpine wetland. Plant and Soil, 407, 401-415. https://doi.org/10.1007/s11104-016-2898-x

Li, Z. C., Yang, J. X., Zheng, Z. Y., Yu, Y., Zhang, T. T., Hou, X. H., \& Wei, Z. G. (2017). Comparative study of the soil thermal regime in arid and semi-humid areas. Environmental Earth Sciences, 76(1), 28. https:// doi.org/10.1007/s12665-016-6354-2

Lin, J. J., Ma, R., Hu, Y. L., Sun, Z. Y., Wang, Y. X., \& McCarter, C. P. R. (2018). Groundwater sustainability and groundwater/surface-water interaction in arid Dunhuang Basin, Northwest China. Hydrogeology Journal, 26, 1559-1572. https://doi.org/10.1007/s10040-0181743-0

Ma, X. H., Feng, Q., Su, Y. H., Yu, T. F., \& Deo, R. C. (2018). Characteristics of ecosystem water use efficiency in a desert riparian forest. Environmental Earth Sciences, 77(10), 358. https://doi.org/10.1007/s12665018-7518-z

Mao, W., Felton, A. J., Ma, Y. H., Zhang, T. H., Sun, Z. B., Zhao, X. Y., \& Smith, M. D. (2018). Relationships between aboveground and belowground trait responses of a dominant plant species to alterations in watertable depth. Land Degradation \& Development, 29, 4015-4024. https://doi.org/10.1002/ldr.3159

Michaels, A. F. (2003). Ecological stoichiometry-The biology of elements from molecules to the biosphere. Science, 300, 906-907. https://doi. org/10.1126/science.1083140

Migliavacca, M., Perez-Priego, O., Rossini, M., El-Madany, T. S. Moreno, G., van der Tol, C., ... Reichstein, M. (2017). Plant functional traits and canopy structure control the relationship between photosynthetic $\mathrm{CO}_{2}$ uptake and far-red sun-induced fluorescence in a Mediterranean grassland under different nutrient availability. New Phytologist, 214, 1078-1091. https://doi.org/10.1111/nph.14437

Munns, R. (2002). Comparative physiology of salt and water stress. Plant Cell and Environment, 25, 239-250. https://doi.org/10.1046/j.00168025.2001.00808.x

Munoz-Reinoso, J. C. (2001). Vegetation changes and groundwater abstraction in SW Donana, Spain. Journal of Hydrology, 242, 197-209. https://doi.org/10.1016/s0022-1694(00)00397-8

Ordonez, J. C., van Bodegom, P. M., Witte, J. P. M., Wright, I. J., Reich, P. B., \& Aerts, R. (2009). A global study of relationships between leaf traits, climate and soil measures of nutrient fertility. Global Ecology and Biogeography, 18, 137-149. https://doi.org/10.1111/j.14668238.2008.00441.x

Pei, S. F., Fu, H., \& Wan, C. G. (2008). Changes in soil properties and vegetation following exclosure and grazing in degraded Alxa Desert steppe of Inner Mongolia, China. Agriculture, Ecosystems \& Environment, 124, 33-39. https://doi.org/10.1016/j.agee.2007.08.008

Perez-Harguindeguy, N., Diaz, S., Garnier, E., Lavorel, S., Poorter, H., Jaureguiberry, P., ... Cornelissen, J. H. C. (2013). New handbook for standardised measurement of plant functional traits worldwide. Australian Journal of Botany, 61, 167-234. https://doi.org/10.1071/ bt12225

Preston, K. A., Cornwell, W. K., \& DeNoyer, J. L. (2006). Wood density and vessel traits as distinct correlates of ecological strategy in 51 California coast range angiosperms. New Phytologist, 170, 807-818. https://doi. org/10.1111/j.1469-8137.2006.01712.x

Prieto, I., Armas, C., \& Pugnaire, F. I. (2012). Hydraulic lift promotes selective root foraging in nutrient-rich soil patches. Functional Plant Biology, 39(9), 804-812. https://doi.org/10.1071/fp12070

Principe, A., Nunes, A., Pinho, P., do Rosario, L., Correia, O., \& Branquinho, C. (2014). Modeling the long-term natural regeneration potential of woodlands in semi-arid regions to guide restoration efforts. European Journal of Forest Research, 133, 757-767. https:// doi.org/10.1007/s10342-014-0787-5

Rajput, V. D., Minkina, T., Chen, Y. N., Sushkova, S., Chapligin, V. A., \& Mandzhieva, S. (2016). A review on salinity adaptation mechanism and characteristics of Populus euphratica, a boon for arid ecosystems. Acta 
Ecologica Sinica, 36, 497-503. https://doi.org/10.1016/j.chnaes.2016. 08.001

Rao, D. L. N., \& Pathak, H. (1996). Ameliorative influence of organic matter on biological activity of salt-affected soils. Arid Soil Research and Rehabilitation, 10, 311-319. https://doi.org/10.1080/15324989609381446

R Development Core Team. (2017). R: A language and environment for statistical computing. Vienna, Austria: R Foundation for Statistical Computing Retrieved from http://www.Rproject.org/

Reich, P. B. (2014). The world-wide 'fast-slow' plant economics spectrum: A traits manifesto. Journal of Ecology, 102, 275-301. https://doi.org/ 10.1111/1365-2745.12211

Reich, P. B., \& Oleksyn, J. (2004). Global patterns of plant leaf $N$ and $P$ in relation to temperature and latitude. Proceedings of the National Academy of Sciences of the United States of America, 101, 11001-11006. https://doi.org/10.1073/pnas.0403588101

Ross, S. M. (1993). Organic-matter in tropical soils-Current conditions, concerns and prospects for conservation. Progress in Physical Geography, 17, 265-305. https://doi.org/10.1177/030913339301700301

Rueden, C. T., Schindelin, J., Hiner, M. C., DeZonia, B. E., Walter, A. E., Arena, E. T., \& Eliceiri, K. W. (2017). ImageJ2: ImageJ for the next generation of scientific image data. BMC Bioinformatics, 18(529), 529. https://doi.org/10.1186/s12859-017-1934-z

Sardans, J., Rivas-Ubach, A., \& Penuelas, J. (2012). The C:N:P stoichiometry of organisms and ecosystems in a changing world: A review and perspectives. Perspectives in Plant Ecology Evolution and Systematics, 14, 33-47. https://doi.org/10.1016/j.ppees.2011.08.002

Sherrod, L. A., Dunn, G., Peterson, G. A., \& Kolberg, R. L. (2002). Inorganic carbon analysis by modified pressure-calcimeter method. Soil Science Society of America Journal, 66, 299-305. https://doi.org/10.2136/ sssaj2002.0299

Smith, S. D., Devitt, D. A., Sala, A., Cleverly, J. R., \& Busch, D. E. (1998). Water relations of riparian plants from warm desert regions. Wetlands, 18, 687-696. https://doi.org/10.1007/bf03161683

Stirzaker, R. J., Passioura, J. B., \& Wilms, Y. (1996). Soil structure and plant growth: Impact of bulk density and biopores. Plant and Soil, 185, 151-162. https://doi.org/10.1007/bf02257571

Stromberg, J. C., Tiller, R., \& Richter, B. (1996). Effects of groundwater decline on riparian vegetation of semiarid regions: The San Pedro, Arizona. Ecological Applications, 6, 113-131. https://doi.org/10.2307/ 2269558

Sun, F. D., Chen, W. Y., Yuan, H. F., Dou, Y. J., Bing, D. H., Feng, Y., \& $\mathrm{Wu}, \mathrm{T}$. (2016). Spatial heterogeneity of vegetation and soil moisture in the desert-wetland ecosystem in Dunhuang Xihu,Gansu Province, China. Acta Botanica Boreali-Occidentalia Sinica, 36, 165-173. https:// doi.org/10.7606/j.issn.1000-4025.2016.01.0165

TerMikaelian, M. T., \& Korzukhin, M. D. (1997). Biomass equations for sixty-five North American tree species. Forest Ecology and Management, 97, 1-24. https://doi.org/10.1016/s0378-1127(97)00019-4

Tester, M., \& Davenport, R. (2003). $\mathrm{Na}^{+}$tolerance and $\mathrm{Na}^{+}$transport in higher plants. Annals of Botany, 91, 503-527. https://doi.org/10. 1093/aob/mcg058

van der Molen, M. K., Dolman, A. J., Ciais, P., Eglin, T., Gobron, N., Law, B. E., ... Wang, G. (2011). Drought and ecosystem carbon cycling. Agricultural and Forest Meteorology, 151, 765-773. https://doi.org/10. 1016/j.agrformet.2011.01.018

Veldkornet, D. A., Potts, A. J., \& Adams, J. B. (2016). The distribution of salt marsh macrophyte species in relation to physicochemical variables. South African Journal of Botany, 107, 84-90. https://doi.org/10. 1016/j.sajb.2016.08.008

Westoby, M., \& Wright, I. J. (2006). Land-plant ecology on the basis of functional traits. Trends in Ecology \& Evolution, 21, 261-268. https:// doi.org/10.1016/j.tree.2006.02.004
Wilson, P. J., Thompson, K., \& Hodgson, J. G. (1999). Specific leaf area and leaf dry matter content as alternative predictors of plant strategies. New Phytologist, 143, 155-162. https://doi.org/10.1046/j.1469-8137. 1999.00427.x

Wright, I. J., Reich, P. B., Cornelissen, J. H. C., Falster, D. S., Groom, P. K., Hikosaka, K., ... Westoby, M. (2005). Modulation of leaf economic traits and trait relationships by climate. Global Ecology and Biogeography, 14, 411-421. https://doi.org/10.1111/j.1466-822x.2005. 00172.x

Wright, I. J., Reich, P. B., Westoby, M., Ackerly, D. D., Baruch, Z., Bongers, F., ... Villar, R. (2004). The worldwide leaf economics spectrum. Nature, 428, 821-827. https://doi.org/10.1038/nature02403

Wright, I. J., Reich, P. B., \& Westoby, M. (2001). Strategy shifts in leaf physiology, structure and nutrient content between species of highand low-rainfall and high- and low-nutrient habitats. Functional Ecology, 15, 423-434. https://doi.org/10.1046/j.0269-8463.2001. 00542.x

Xing, X. G., Kang, D. G., \& Ma, X. Y. (2017). Differences in loam water retention and shrinkage behavior: Effects of various types and concentrations of salt ions. Soil and Tillage Research, 167, 61-72. https://doi. org/10.1016/j.still.2016.11.005

Xu, W. X., Liu, W., Yang, W. K., Tang, C. W., \& Blank, D. (2012). Rhombomys opimus contribution to the "fertile Island" effect of tamarisk mounds in Junggar Basin. Ecological Research, 27, 775-781. https://doi.org/10.1007/s11284-012-0952-6

Yang, X. M., Liu, S. Z., Yang, T. B., Xu, X. Y., Kang, C. Z., Tang, J. N., ... Li, Z. Q. (2016). Spatial-temporal dynamics of desert vegetation and its responses to climatic variations over the last three decades: $A$ case study of Hexi region in Northwest China. Journal of Arid Land, 8, 556-568. https://doi.org/10.1007/s40333-016-0046-3

Zhang, X. L., Guan, T. Y., Zhou, J. H., Cai, W. T., Gao, N. N., Du, H., ... Zheng, Y. R. (2018). Groundwater depth and soil properties are associated with variation in vegetation of a desert riparian ecosystem in an arid area of China. Forests, 9(1), 34. https://doi.org/10.3390/f9010034

Zhou, H. H., Chen, Y. N., \& Li, W. H. (2010). Soil properties and their spatial pattern in an oasis on the lower reaches of the Tarim River, Northwest China. Agricultural Water Management, 97, 1915-1922. https:// doi.org/10.1016/j.agwat.2010.07.004

Zhou, X. L., Guo, Z., Zhang, P. P., \& Du, G. Z. (2018). Shift in community functional composition following nitrogen fertilization in an alpine meadow through intraspecific trait variation and community composition change. Plant and Soil, 431, 289-302. https://doi.org/10.1007/ s11104-018-3771-x

Zhu, J. T., Yu, J. J., Wang, P., Zhang, Y. C., \& Yu, Q. (2012). Interpreting the groundwater attributes influencing the distribution patterns of groundwater-dependent vegetation in northwestern China. Ecohydrology, 5, 628-636. https://doi.org/10.1002/eco.249

\section{SUPPORTING INFORMATION}

Additional supporting information may be found online in the Supporting Information section at the end of this article.

How to cite this article: Chen G, Yue D, Zhou Y, et al. Driving factors of community-level plant functional traits and species distributions in the desert-wetland ecosystem of the Shule River Basin, China. Land Degrad Dev. 2020;1-15. https://doi. org/10.1002/ldr.3624 